\title{
Debating phylogenetic relationships of the scleractinian Psammocora: molecular and morphological evidences
}

\author{
Francesca Benzoni ${ }^{1}$, Fabrizio Stefani ${ }^{1}$, Jaroslaw Stolarski ${ }^{2}$, Michel Pichon ${ }^{3}$, Guillaume Mitta ${ }^{4}$, Paolo Galli ${ }^{1}$ \\ ${ }^{1}$ Dipartimento di Biotecnologie e Bioscienze, Università di Milano-Bicocca, Piazza della Scienza, 2. 20126 Milano, \\ Italy, francesca.benzoni@unimib.it ; ${ }^{2}$ Instytut Paleobiologii PAN, ul. Twarda 51/55, PL-00-818 Warszawa, Poland, \\ stolacy@twarda.pan.pl; ${ }^{3}$ Laboratoire des Ecosystèmes Aquatiques Tropicaux et Méditerranéens, Ecole Pratique \\ des Hautes Etudes, Université de Perpignan, 66860 Perpignan Cedex, France; ${ }^{4}$ Laboratoire de Parasitologie \\ Fonctionnelle et Évolutive, UMR 5555 CNRS, Université de Perpignan, Perpignan, France
}

Key words: Psammocora, Siderastreidae, Fungiidae, synapticulae, fulturae, ITS, statistical parsimony

\begin{abstract}
The phylogenetic relationships of the scleractinian genus Psammocora with the other genera traditionally included in the family Siderastreidae and some Fungiidae are assessed based on combined skeletal and molecular data. $P$. explanulata differs from the other examined congeneric species ( $P$. contigua, $P$. digitata, $P$. nierstraszi, $P$. profundacella, $P$. superficialis, and $P$. stellata) in possessing interstomatous septa between adult corallites, costae, and in having continuous buttress-like structures joining septal faces (i.e., fulturae) which typically occur in fungiids. These characters are shared with Coscinaraea wellsi but not with the remainder of the examined siderastreids (the congeneric C. columna, and Anomastraea irregularis, Horastrea indica, Pseudosiderastrea tayamai, Siderastrea savignyana) whose septa are interconnected by typical synapticulae. Most of the examined species form septa with distinct transverse groups of centers of calcification, a biomineralization pattern typical of the Robusta clade. The observations on skeletal structures corroborate the results of the ITS2 and 5.8S molecular phylogeny. C. wellsi and P. explanulata are phylogenetically very close to each other and show closer genetic affinity with the examined Fungiidae (Halomitra pileus, Herpolitha limax, Fungia paumotensis, and Podabacia crustacea) than with the other species in the genera Psammocora and Coscinaraea, or with any other siderastreid. Our results show that neither Psammocora nor Coscinaraea are monophyletic genera. The high genetic distances between the species of Siderastreidae, especially between Pseudosiderastrea tayamai and Siderastrea savignyana on one side and the other genera on the other, suggest a deep divergence in the phylogenetic structure of the family.
\end{abstract}

\section{Contents}

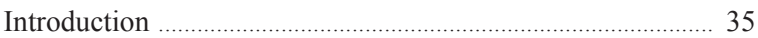

Material and methods ............................................................. 37

Species identification ………............................................... 37

Choice of Psammocora species ........................................ 37

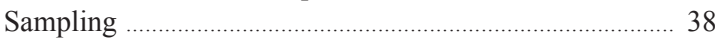

SEM preparation and analysis ....................................... 38

DNA extraction, amplification and sequencing ................ 38

Network building and distances calculation ..................... 39

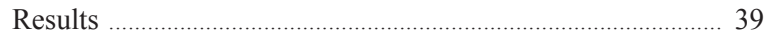

Morphology of Psammocora ……...................................... 39

Polyp morphology ............................................................. 39

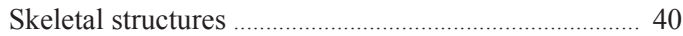

Skeletal structures of the Siderastreidae .............................. 41

The molecular approach ............................................................ 45

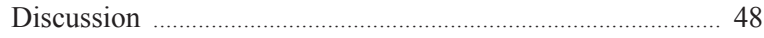

Skeletal structures ................................................................... 48

Colony wall (epitheca, complex wall structures,

septotheca) .................................................................. 48

Calice thecal structures (synapticulae, fulturae,

adtrabecular bars) ...................................................... 49

Septal microarchitecture and microstructure ............... 49

Phylogeny of Psammocora and the Siderastreidae ................ 50

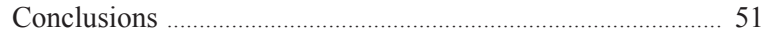

Acknowledgements ............................................................. 52

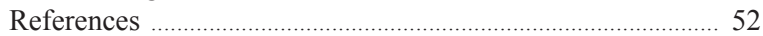

\section{Introduction}

The Indo-Pacific coral genus Psammocora Dana, 1846 has a wide geographic distribution and it is commonly found in any reef environment, from seagrass beds and lagoons, to outer reef slopes down to $50 \mathrm{~m}$ depth. Most species may be cryptic even if some branching species can be locally abundant and form monospecific stands (Sheppard and Sheppard, 1991; Veron, 2000). Skeletal structures in Psammocora are complex and plastic, and some characteristic morphological features unique to the genus such as extrapolypal tentacles, and the intricate mesh of ento- and exosepta (Matthai, 1948a; Matthai, 1948b) have been largely overlooked in the literature thus leading to the use of confused terminology in descriptions by various authors. 
Twenty-three extant Psammocora species have been described. Many of those have been put in synonymy (Veron and Pichon, 1976; Scheer and Pillai, 1983; Sheppard and Sheppard, 1991). A global revision of the genus, however, has never been undertaken. Eleven Psammocora species are listed in Cairns et al. (1999), and Veron (2000) retains twelve species. However species synonymies are not indicated or discussed in either publication.

Hypotheses about phylogenetic relationships of Psammocora and the resulting classification have changed dramatically over the last sixty years (Stolarski and Roniewicz, 2001). Vaughan and Wells (1943) considered Psammocora the only extant genus in the Thamnasteriidae, suborder Fungiida (Fig. 1a), based on the presence of synapticulothecal wall and simple trabeculae of septa. Alloiteau (1952) also placed Psammocora, Stephanoseris and Plesioseris in the family Thamnasteriidae. Wells (1956) still maintained Psammocora in the Thamnasteriidae, but placed the family in the Astrocoeniina (Fig. 1b). Chevalier and Beauvais (1987) brought back the Thamnasteriidae in the Fungiina but placed Psammocora in the new family Psammocoridae (Fig. 1c) along with Stephanaria Verrill, 1867, and Plesioseris Duncan 1884, both previously considered subgenera of Psammocora, and synonymised with it by Veron and Pichon (1976). Finally Veron (1995) based on skeletal features and on its "clear affinities" with Coscinaraea classified Psammocora in the Siderastreidae with Siderastrea Blainville, 1830,
Coscinaraea Milne Edwards and Haime, 1848, Anomastraea Marenzeller, 1901, Pseudosiderastrea Yabe and Sugiyama, 1935, and Horastrea Pichon 1971 (Fig. 1d). These genera have been grouped together because of the common presence of synapticulae and the fusion of septa around the corallite fossa. A comprehensive treatment of the family skeletal structures, however, has never been published, and such characters have never been proved to be plesiomorphic. The genus Craterastrea Head, 1983 is poorly known and presently recorded from the Red Sea and Chagos only (Head, 1983; Sheppard, 1981; Sheppard, 1998; Sheppard and Sheppard, 1991). It was described as a siderastreid and has been later synonymised with the agariciid genus Leptoseris (Veron, 1995; Veron 2000; Inskipp and Gillett 2005).

Among the extant corals Psammocora bears structural similarities to Coscinaraea especially in the septa shape and corallites arrangement (Pandolfi, 1992; Veron, 2000), and to Craterastrea. Coscinaraea columna (Dana, 1846) and Coscinaraea exesa (Dana, 1846) were originally described as Psammocora, and the similarities between Psammocora explanulata Van der Horst, 1922, and Coscinaraea wellsi Veron and Pichon, 1980 are evident (Veron and Pichon, 1980; Veron, 2000). Morphologic affinities of the septa fusion patterns in Psammocora and in the fungiids Lithophyllon Rehberg, 1892 and Polyphyllia Blainville, 1830 have also been remarked (Veron and Pichon, 1976; Van der Horst, 1922).

\section{a) Vaughan and Wells, 1943 \\ b) Wells, 1956 \\ c) Chevalier and Beauvais, 1987 \\ d) Veron, 1995

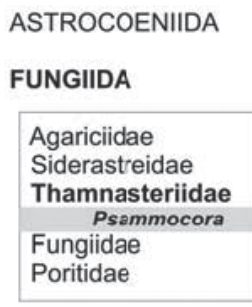 \\ FAVIIDA \\ CARYOPHYLLIIDA \\ DENDROPHYLLIIDA

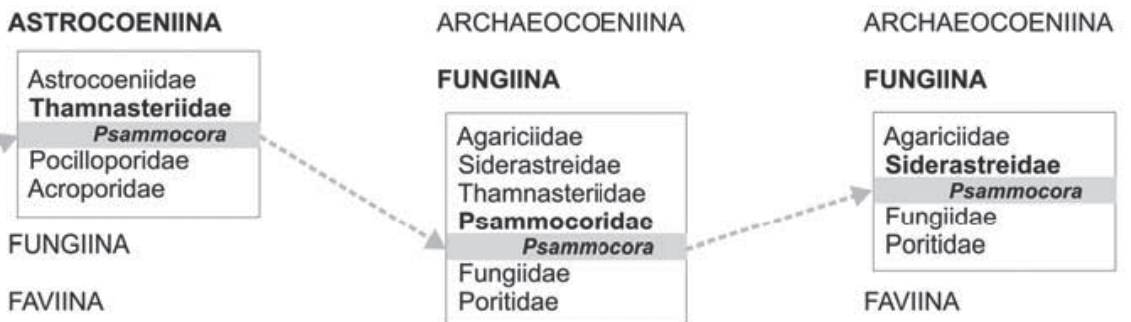 \\ FAVIINA \\ CARYOPHYLLIINA \\ DENDROPHYLIINA \\ FAVIINA \\ MEANDRIINA \\ CARYOPHYLLIINA \\ DENDROPHYLLIINA \\ FAVIINA \\ CARYOPHYLLINA \\ MEANDRIINA \\ PORITIINA \\ DENDROPHYLLIINA}

Fig. 1. Changes in classification of the genus Psammocora. Grey arrows indicate the change of position of the genus (in bold italic) within a family (in bold) and suborder (in bold capitals) according to a) Vaughan and Wells (1943), b) Wells (1956), c) Chevalier et Beauvais, 1987, d) Veron (1995). Modified from Stolarski and Roniewicz (2001). 
The molecular phylogeny of the Fungiina has, so far, been only partially investigated. Studies based on mitochondrial DNA (Romano and Palumbi, 1996; Romano and Cairns, 2000) showed that the Fungiina are not monophyletic and that Psammocora stellata and Coscinaraea sp., cluster together with some of the Fungiidae. Chen et al. (2004) showed that based on ITS Psammocora and Siderastrea belong to distant clades, thus suggesting that the Siderastreidae sensu Veron (2000) are not monophyletic. However the phylogentic relationships within Psammocora and between it and the other genera in the family remain unknown.

In this paper we first provide a synthetic but comprehensive account of living and skeletal structures of the genus Psammocora, we then explore the morphologic and genetic affinities of seven Psammocora species. Finally we discuss the phylogenetic relationships of Psammocora with all the Siderastreidae and some Fungiidae based on the joint results of our morphological study and genetic investigations.

\section{Material and methods}

\section{Species identification}

Psammocora species were first identified following the descriptions and illustrations given by Pillai and Scheer (1976), Veron and Pichon (1976), Scheer and Pillai (1983), and Sheppard and Sheppard (1991). Identifications were then checked against the species original description and, when possible, type material was examined. Scleractinia collections and type material deposited at the Zoological Museum of Amsterdam (MZA), Naturalis in Leiden (RMNH), the Museum of Natural History in London (MNH), the National Museum of Natural History in Paris (MNHN), and the Museum of Tropical Queensland (MTQ), were examined. For the identification of C. columna (Dana, 1846), Siderastrea savignyana Milne Edwards and Haime 1850, Anomastraea irregularis Marenzeller, 1901, Pseudosiderastrea tayamai Yabe and Sugiyama, 1935, Horastrea indica Pichon, 1971, and C. wellsi Veron and Pichon, 1980, we referred to Veron and Pichon (1980), Carpenter et al. (1997), and to the species original descriptions. The type specimen of Craterastrea levis Head, 1983 (MNH 1981.4.1.4) was examined. However due to the species restricted geographic distribution (Head, 1983; Sheppard, 1991; Sheppard, 1998; Sheppard and Sheppard, 1991) and to its apparent rarity we did neither manage to retrieve any ethanol preserved material nor to collect it. Our data on the genus is therefore limited to the external skeletal structures. For the identification of the Fungiidae species Halomitra pileus (Linnaeus, 1758), Podabacia crustacea (Pallas, 1766), Herpolitha limax Esper, 1797, and Fungia (Pleuractis) paumotensis Stutchbury, 1833 we followed Hoeksema (1989).

\section{Choice of Psammocora species}

This work is part of a world revision of the genus for which a large set of specimens has been collected. For the purpose of the present analysis we included 7 Psammocora species (Table 1) for which the taxonomic status has been verified (registration code of the examined type material is given in parenthesis): Psammocora contigua (Esper, 1794) (SMF 5523), Psammocora digitata Milne Edwards and Haime, 1851 (MNHN 533), Psammocora stellata Verrill, 1864 (MNH 1870. 8.22.16), Psammocora superficialis Gardiner, 1898, Psammocora profundacella Gardiner, 1898, Psammocora nierstraszi Van der Horst, 1921 (ZMA Coel 1078), and P. explanulata (ZMA Coel 1071; ZMA Coel 1072; MNH 1937.11.25.17; MNH 1937.11.17.69).

Five Psammocora species (i.e., P. obtusangula (Lamarck, 1816) (MNHN 136), P. haimeana Milne Edwards and Haime, 1851 (MNHN 535), Psammocora verrilli Vaughan, 1907, P. decussata Yabe and Sugiyama, 1937, and P. vaughani Yabe and Sugiyama, 1936) have not been included in the analysis because of the following taxonomic reasons. The type specimen of $P$. obtusangula showed no substantial difference from the type of $P$. contigua. The taxonomic status of $P$. haimeana, $P$. verrilli, $P$. decussata and $P$. vaughani remains uncertain. The holotype of $P$. verrilli has not been studied by the authors yet, but in the illustration of the original description (Pl. XLIV, Figs. 1-1a) it shows striking similarities to $P$. nierstraszi. The holotypes $P$. decussata and $P$. vaughani deposited at the Institute of Geology and Paleontology, Tohoku University, Sendai (P. decussata IGPTU 61591; P. vaughani IGPTU 44975) could not be located (Nemoto Jun, $05 / 01 / 2006$ in litteris). P. decussata is supposed to be an endemic species of Japan (Veron, 2000) but from the original illustration it is very similar to $P$. contigua (Yabe and Sugiyama, 1937, p. 428 Figs. 2-4). The corallite drawing and Figure 3 of the P. vaughani description in Veron (2000) (Vol 2, p. 157) depict a Coscinaraea sp. and certainly do not match either the original description or the clear illustrations in it (Yabe et al., 1936, Pl. XLI, Figs. 6 and 7). However the author 
himself states that the specimens he identified as $P$. vaughani present "Coscinaraea-like" skeletal characters, and that he retained the species in the genus Psammocora only because of the small corallite size.

\section{Sampling}

Corals for this study were sampled while scuba diving between 2 and $30 \mathrm{~m}$ deep at different localities in $\mathrm{Ku}$ wait, Maldives, Mayotte, Reunion, Indonesia. Specimens of P. stellata from Costa Rica were collected and kindly provided by Jorge Cortes. Digital images of living corals were taken with a Nikon Coolpix 995 in an Ikelite underwater housing system. Coral specimens were collected, tagged and for each specimen $1 \mathrm{~cm}^{2}$ was broken off the colony and preserved in absolute ethanol for molecular analysis. The remaining corallum was left for 48 hours in a 50\% sodium hypochlorite at ambient temperature to remove all soft parts, rinsed in freshwater and dried for microscope observation. The Psammocora and Siderastreidae specimens studied for this work were deposited at the Museum of Natural History in Milan. The Fungiidae specimens belong to the GIS-LAY Mayotte Expedition Collection and are in Perpignan. Images of skeletons were taken with a Canon G5 camera through a Soligor B-52 Adapter Tube mounted on a Zeiss Stemi DV4 stereomicroscope. The list of sampled species and localities is in Table 1.

\section{SEM preparation and analysis}

Samples selected for microstructural analysis were ground with diamond suspension having grain sizes of 5 and 1 micrometers, and later polished with aluminium oxide (Buehler TOPOL 3 final polishing suspension with particle size 0.25 micrometres). After polishing, sections were rinsed in Milli-Q water, washed in an ultrasonic cleaner for 10 seconds, then etched for $10 \mathrm{sec}-$ onds in $0.1 \%$ formic acid, then rinsed with Milli-Q water and air dried. After drying, the specimens were put on stubs with double sticky tape and sputter-coated with conductive platinum film. Polished and etched samples were investigated using SEM (Philips XL 20).

\section{DNA extraction, amplification and sequencing}

Total DNA extraction and purification was obtained using the DNAeasy ${ }^{\circledR}$ Tissue kit (QIAGEN, Qiagen Inc., Valencia, California, USA) reagents.

Table 1: List of the specimens collected and analysed for this study. For each specimen the species identification, locality, code and EMBL accession number are given respectively. In brackets the frequency of each haplotype, when higher than 1 , is reported. CR $=\mathrm{Costa}$ Rica, $\mathrm{I}=$ Indonesia, $\mathrm{K}=$ Kuwait, $\mathrm{M}=$ Maldives, $\mathrm{MAY}=$ Mayotte, $\mathrm{REU}=$ Reunion.

\begin{tabular}{|c|c|c|c|}
\hline Genus & species & Code/ source & EMBL accession number \\
\hline \multirow[t]{12}{*}{ Psammocora } & contigua & I 110; & AM230604 \\
\hline & & M 48; 49 & AM230602; AM230603 \\
\hline & & MAY $232 ; 254$ & AM230600; AM230601 \\
\hline & nierstraszi & M $43 ; 52 ; 53$ & AM230606; AM230607; AM230608 \\
\hline & profundacella & M 7;9;10;18 & AM230617; AM230618; AM230616; AM230619 \\
\hline & & I 91 & AM230615 \\
\hline & superficialis & K 118; 142 & AM230614; AM230613 \\
\hline & stellata & CR $326 ; 328$ & AM230620; AM230621 \\
\hline & digitata & M 35 & AM230610 \\
\hline & & I 102,97 & AM230609 (2) \\
\hline & & M 16, 26 & AM230609 (2) \\
\hline & explanulata & MAY 447; 453 & AM230611; AM230612 \\
\hline \multirow[t]{3}{*}{ Coscinaraea } & columna & K $117 ; 122$ & AM230598; AM230599 \\
\hline & & M 41 & AM230597 \\
\hline & wellsi & I $80 ; 108 ; 114$ & AM230622; AM230623 (2) \\
\hline Horastrea & indica & REU 516; 518 & $\mathrm{AM} 230605$ \\
\hline Siderastrea & savignyana & K $123 ; 144$ & AM230625 (2) \\
\hline Pseudosiderastrea & tayamai & Chen et al. 2004 & AY722790; AY722789 \\
\hline Anomastraea & irregularis & K $131 ; 124$ & AM231716; AM230624 \\
\hline Podabacia & crustacea & MAY $435 ; 456 ; 457$ & AM230626 (3) \\
\hline Halomitra & pileus & MAY $442 ; 472$ & AM230630; AM230631 \\
\hline Fungia & paumotensis & MAY 440; 481 & AM230627; AM230628 \\
\hline Herpolitha & limax & MAY $470 ; 473 ; 474 ; 480$ & AM230629 (4) \\
\hline
\end{tabular}


The concentration of the extracted solutions, was adjusted to $3 \mathrm{ng} / \mu \mathrm{l}$, and used directly for PCR amplification of $\mathrm{a} \sim 400 \mathrm{bp}$ fragments of rDNA, spanning a portion of the 5.8S gene, the entire ITS2 region and a portion of the $28 \mathrm{~S}$ gene. Amplification was performed using the 5.8Sfor primer (5'-TTT GAC GGT GGA TCT CTT GG-3') and the universal ITS4 primer (5'-TCC TCC GCT TAT TGA TAT GC-3') (White et al., 1990). The 5.8Sfor primer was specifically designed for Scleractinia by the authors on the basis of the homologue alignment of P. profundacella, Lophelia pertusa, Madracis pharensis, M. senaria, Diploastrea heliopora. A sequence of Symbiodinum was also included in order to avoid the amplification of the zooxanthella DNA. The obtained sequences were submitted to a BLAST query of the National Center for Biological Information (NCBI) sequence database, confirming their strict similarity to corals sequences and excluding the sequencing of zooxanthellae DNA.

Reactions were conducted in a $50 \mu \mathrm{l}$ PCR mix consisting of $1 \mathrm{X}$ PCR Buffer, $2 \mathrm{mM} \mathrm{MgCl} 2,0.4 \mu \mathrm{M}$ of each primer, $0.1 \mathrm{mM}$ of each dNTP, $2 \mathrm{U}$ Taq DNA Polymerase (Sigma-Aldrich Co., St. Louis, Montana, USA) and $8 \mu$ l of DNA solution. The thermal cycle was the following: a first denaturation phase at $96^{\circ} \mathrm{C}$ for 2 ', followed by 30 cycles composed of three steps: (1) $10^{\prime \prime}$ at $96^{\circ} \mathrm{C}$; (2) $30^{\prime \prime}$ at $50^{\circ} \mathrm{C}$; (3) $4^{\prime}$ at $72^{\circ} \mathrm{C}$; finally, an extension phase at $72^{\circ} \mathrm{C}$ for $5^{\prime}$. The amplified samples were purified with commercial kits. Sequencing reactions were carried out using a dideoxy-dye-terminator method (CEQ ${ }^{\mathrm{TM}}$ DTCS-Quick Start kit, Beckman Coulter) and a Beckman Coulter CEQ ${ }^{\mathrm{TM}}$ apparatus. We used the reverse primer ITS4 for sequencing and the sequences were read with the Beckman Coulter $\mathrm{CEQ}^{\mathrm{TM}}$ software. Whenever the obtained sequences showed ambiguities, we performed a sequencing reactions using the forward 5.8Sfor primer.

\section{Network building and distances calculation}

The secondary structure of ITS2 has been inferred before alignment using the Mfold program (Zuker, 2003), which generates multiple free-energy diagrams and proposes a consensus model showing common stems, loops and bulges. Regions corresponding to conserved stems throughout the studied species have been used as consistent basis for the alignment of the more variable loop regions. Though structure reconstruction according to thermodynamic properties has been criticized in favour of analysis of covariation sites (Hershkovitz and Zimmer 1996; Gutell et al., 1994), it has been shown that, for Scleractinia at least, this approach provided comparable and reliable results (Goertzen et al., 2003; Chen et al., 2004). The secondary structure of the ITS 2 was obtained for $P$. crustacea, $H$. indica, P. explanulata, $H$. limax, $H$. pileus, and F. paumotensis. The ITS2 sequences of the other species were excluded because of the scarce reliability of the sequence of the flanking $28 \mathrm{~S}$ gene portion. This portion usually pairs with the flanking $5.8 \mathrm{~S}$ portion to form the main loop of the structure.

Alignment was conducted with the software ClustalX (Thompson et al., 1997) and then manually checked and adjusted with BioEdit 5.0.9 (Hall, 1999), according to the constrains evidenced by the ITS2 secondary structure. Identification of polymorphic and parsimony informative sites was conducted with DnaSP 3.52 software (Rozas and Rozas, 2001).

In order to infer phylogenetic relationships we considered a portion of 320 homologue positions, spanning part of the $5.8 \mathrm{~S}$ gene ( $141 \mathrm{bp})$ and part of the ITS2 region (179 bp). We excluded from the analysis a portion of 12 $\mathrm{bp}$ in the ITS2 region because of long and not alignable insertions in S. savignyana and P. tayamai.

A sequence evolution model according to a maximum likelihood criterion was selected using Modeltest 3.06 (Posada and Crandall, 1998) to calculate the mean genetic distance between species (or groups) of interest.

Phylogeny was evaluated both by traditional and by networking approaches. Firstly, a phylogram was built, according to the Bayesian approach (Huelsenbeck et al., 2001), as implemented in the MrBayes program (Huelsenbeck and Ronquist 2001). Bayesian analysis was run starting four Markov chains from random trees and running them for 1300000 generations, with the first 1200000 generations (12000 trees) discarded. The analysis was run independently 4 times and monitored to ensure that standard deviation of split frequencies was $<0.01$.

A minimum spanning network of haplotypes was arranged with the software TCS 1.13 (Clement et al., 2000), according to the statistical parsimony criterion proposed by Templeton et al. $(1992,1993)$ in order to evidence eventual ambiguities and reticulations.

\section{Results}

Morphology of Psammocora

Polyp morphology

Psammocora polyps are often expanded during the day (Fig 2A, C) though seldom obvious due to their small size and transparency. In vivo observation of the polyps 
showed that the coenosarc is absent in all the species of Psammocora. When tentacles are extended their arrangement in concentric circles around the polyp mouth (Fig. $2 \mathrm{~A}, \mathrm{C})$ is visible. A striking feature of Psammocora tentacles is their position with respect to the polyp gastrovascular cavity. The innermost circle of tentacles surrounds the polyp mouth and reaches its gastrovascular cavity directly, whereas the outer tentacle circles are connected indirectly to it via gastrovascular canals. The distinctive character of these "outer" tentacles herein termed extrapolypal (sensu Matthai, 1948b) was first noticed by Yonge (1930: p 40, "it is difficult often to dis- tinguish to which of adjacent mouths particular tentacles rightly belong") and described by Matthai (1948b).

\section{Skeletal structures}

Septa organization in Psammocora bears unique characteristics among the Scleractinia which are directly related to the presence and organization of extrapolypal tentacles. In the calice two kinds of septa are found: the entosepta (bearing a tentacle) and the exosepta (sensu Chevalier, 1987). Entosepta and exosepta alternate around the fossa. Septa are connected by
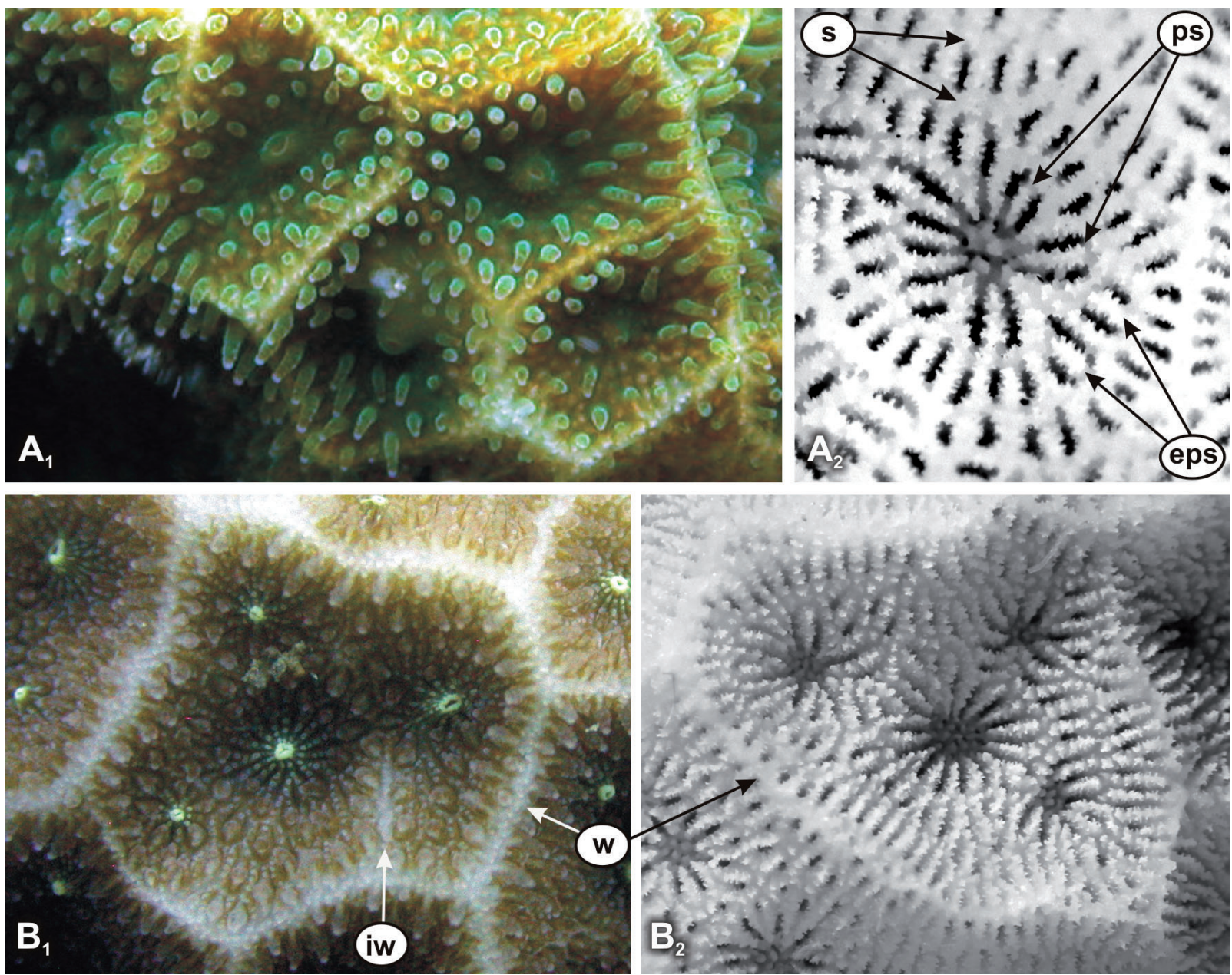

Fig. 2. Typical polyp and skeleton characters of Psammocora. (A) Extended polyps in a living colony of P. profundacella (M18) allow to see two to three concentric rows of white-tipped tentacles around each mouth. (B) A corallite of the same specimen after living tissue removal with petaloid septa (ps) around the calicular fossa, and concentric rows of enclosed petaloid septa (eps) corresponding to the concentric rows of tentacles visible in A. Synapticulae (s) joining the septa, and forming synapticular rings are also visible. (C) The in vivo picture of another P. profundacella colony (I91) shows series of polyps enclosed by a common wall (w). Note the outermost rows of tentacles surrounding all the four polyps within the wall, and the incipient wall (iw) starting to separate the corallite on the left from the others in the series. The intratentacular mode of budding is clearly visible. (D) Series of calices enclosed by a common wall (w) in another specimen (M10) after tissue removal. 
crossbar-like rods called synapticulae (Vaughan and Wells, 1943). The exosepta furcate peripherally before reaching a first row of synapticulae delimiting the calice. At the furcation of an exoseptum a new entoseptum is formed. Between the first and the second row of synapticulae each of the two exosepta formed after the furcation can either divide again, or fuse with another exoseptum thus leading to the enclosure of the entoseptum found between them. Each enclosed entoseptum in the corallum corresponds to an extrapolypal tentacle in the living animal. The first circle of enclosed entosepta bears the second circle of tentacles visible in vivo around the polyp mouth (Fig. 2A, C). The reiteration of exosepta furcation and fusion processes, along with the formation of new enclosed entosepta, can occur from 2 to more than 10 times depending on the species. In $P$. contigua, $P$. nierstraszi series of enclosed entosepta are more numerous than in any other species (Fig. $3 \mathrm{~A}_{1}$ and $\mathrm{B}_{1}$ respectively) and the calices look immersed in a mesh of ento- and exosepta often erroneously referred to as the coenosteum. In P. profundacella (Fig. $3 \mathrm{C}_{1}$ ) two to five circles of enclosed entosepta can be easily seen around the calice. In P. superficialis (Fig. $3 \mathrm{D}_{1}$ ), P. stellata (Fig. $3 \mathrm{E}_{1}$ ) and P. digitata (Fig. $3 \mathrm{~F}_{1}$ ) a maximum of 2 complete circles of enclosed entosepta usually form. In P. explanulata only one circle of enclosed entosepta, often incomplete, is found. Entosepta and enclosed entosepta can be thicker than the exosepta and reach the typical "petaloid" shape (well visible, for example, in Fig. $3 \mathrm{D}_{1}, \mathrm{~F}_{1}, \mathrm{~F}_{2}$ ). Petaloid septa in Psammocora are often exert above the colony surface. In less heavily calcified specimens although enclosed septa exist, they may not reach the typical petaloid shape and the different septa thickness is less evident. Septocostae are absent in all the Psammocora species we studied. In $P$. explanulata continuous septa going from one fossa to the other can be found (Fig. $3 \mathrm{G}_{1}$, Fig. $5 \mathrm{~B}_{2}$ ). In this case, however, these septa are interstomatous septa in every respect similar to those found in the Fungiidae (sensu Hoeksema, 1989) and are not homologous with the septo-costae found in other coral families. In P. explanulata tentacular lobes very similar those found in some Fungiidae are also found.

Ridges composed of short series of minute granule/ spines oriented transversally to the septal plane can be recognized at the growing septal edges of the Psammocora species we examined. In some species (e.g., $P$. digitata, $P$. superficialis, $P$. stellata, also P. explanulata) these transverse ridges form distinct septal paddles (Fig. $3 \mathrm{D}_{2,3}, \mathrm{E}_{2-3}, \mathrm{~F}_{2-3}, \mathrm{G}_{2}$ ). Microstructurally, the minute granule/spines correspond to centers of calcification
(Centers of Rapid Accretion, sensu Stolarski 2003) as seen in transversally sectioned septa $\left(\right.$ Fig. $\left.3 \mathrm{D}_{4}, \mathrm{E}_{4}, \mathrm{~F}_{4}\right)$.

The microstructural analysis of the skeletal elements connecting the septa in Psammocora confirms the presence of synapticulae (Fig. 5 $\mathrm{A}_{1-2}$ ) in all the considered species but $P$. explanulata (Fig. $5 \mathrm{~B}_{1-2}$ ). In the latter buttress-like structures develop below the septal edge (Fig. $\left.5 \mathrm{~B}_{1-3}\right)$. These structures are arranged perpendicularly to the distal septal margins, and show arched zones of fibrous layers in longitudinal section (Fig. $5 \mathrm{~B}_{5}$ ). In transverse section they exhibit ad-septal formation of the fibrous layers which join with a suture (Fig. 5B $\mathrm{B}_{4}$.

The columella is present in all the examined Psammocora species, but the number of columellar processes, their size and disposition varies between species. P. contigua, $P$. nierstraszi, $P$. superficialis, and P. digitata all have a styliform columella (Fig. $3 \mathrm{~A}_{1}, \mathrm{~B}_{1}, \mathrm{D}_{1}, \mathrm{~F}_{1}$ respectively). P. profundacella and $P$. stellata present a composite columella made of one central process surrounded by 4 to 6 smaller processes. In $P$. explanulata the columellar processes are all of the same size, and in adult corallites their number ranges from 6 to 15 .

In all the examined species of Psammocora except $P$. explanulata colonies form an epithecal-synapticulothecal wall (for terminology see Roniewicz and Stolarski, 1999). In P. explanulata, however, the colony wall is septothecal.

Colony condition in Psammocora is ceriod (Fig. 2A, B) and the meandroid state can be reached via intratentacular budding (Fig. 2C, D) (Matthai, 1948a) and series of corallites can form. In some species corallites form series surrounded by so many concentric rows of synapticulae (i.e., P. contigua) that the exact boundaries of the wall can hardly be recognised (Fig. $3 \mathrm{~A}_{1}$ ). In other species, i.e., P. profundacella, the shape, length and width of the series of corallites can be very variable even within the same colony However the wall boundaries are clearly recognisable (Fig. $3 \mathrm{C}_{1}$ ). Often a new a wall developing to separate corallites within the same series is visible (Fig. 2C). In P. explanulata series of corallites enclosed by a synapticulothecal wall never form.

$P$. explanulata differs from the remainder of the examined species in a number of skeletal structures summarized in Table 2.

\section{Skeletal structures of the Siderastreidae}

The septal fusion considered as typical of the Siderastreidae is present in all the examined species in the family (Fig. 4). The series of enclosed entosepta typical of Psammocora, however, were not found in any other 

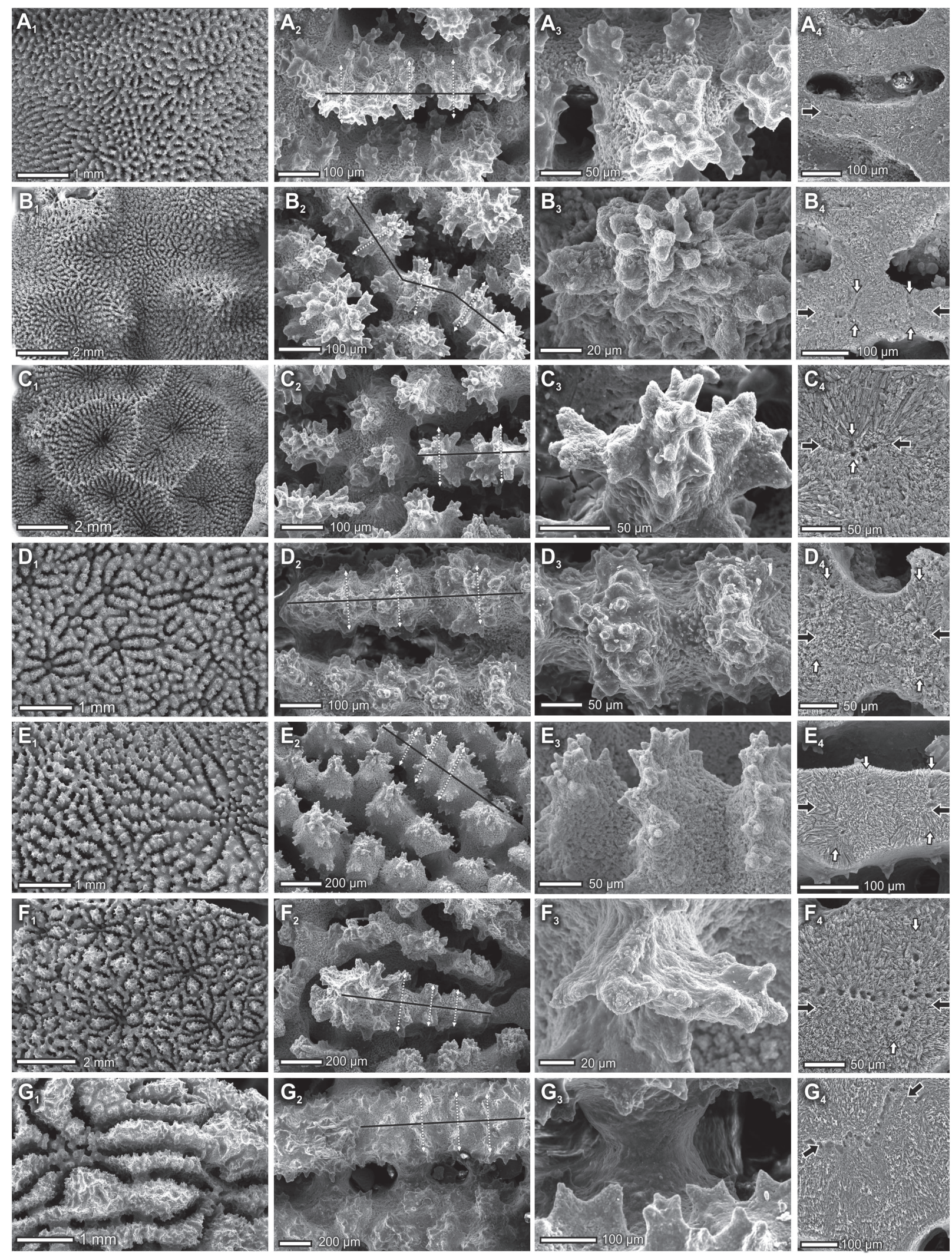

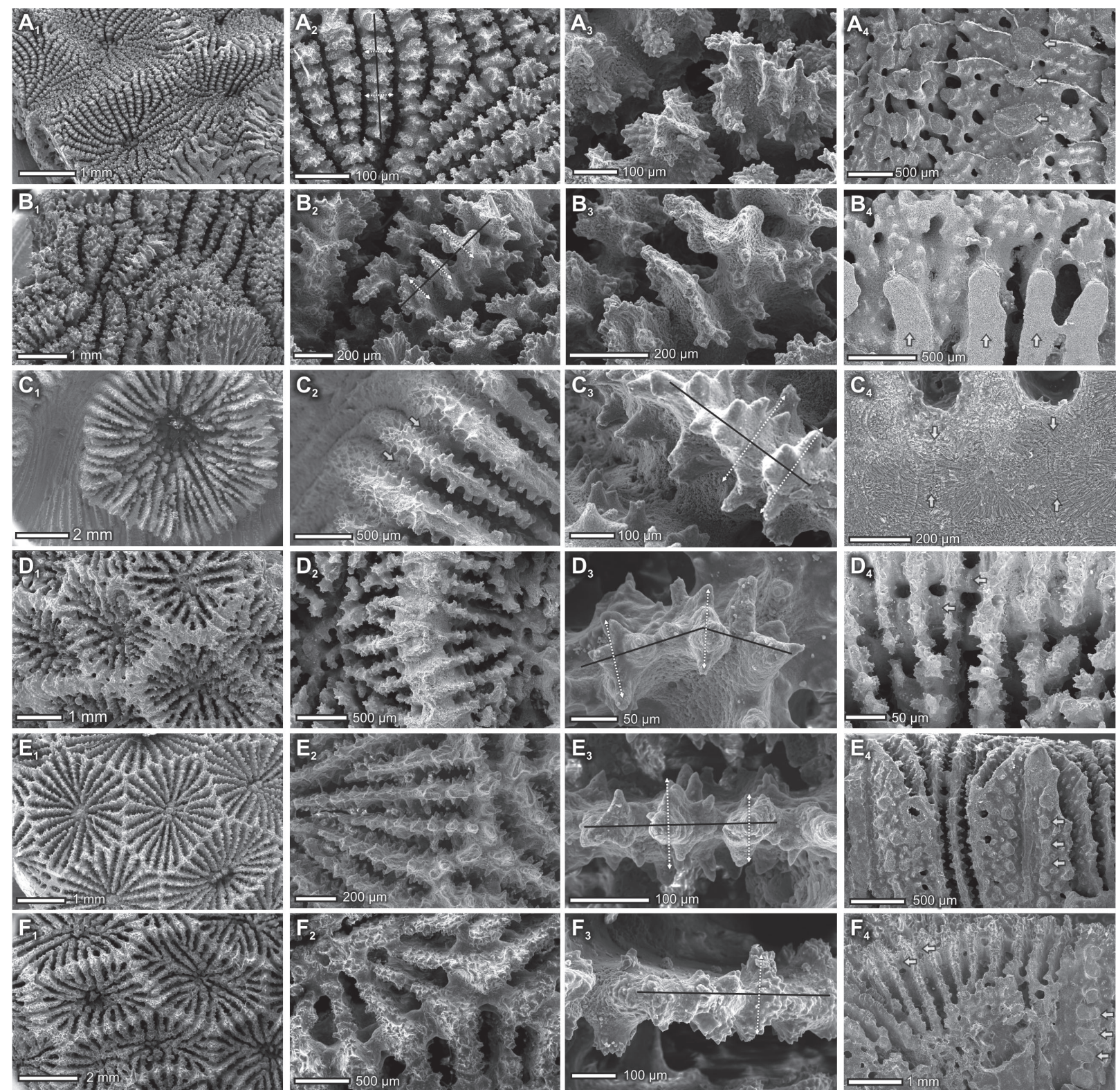

Fig. 4. Septal arrangement (subscripted with "1"), microarchitecture (subscripted with "2", and "3" [close-up of septal projection]) and septal junctions/wall structure (subscripted with "4") in the examined Siderastreidae (sensu Veron 2000): Coscinaraea columna (A), Coscinaraea wellsi (B), Horastrea indica (C), Pseudosiderastrea tayamai (D), Siderastrea savignyana (E), Anomastraea irregularis (F). Transverse groups of centers of calcification typical of the Robusta highlighted with white arrows whereas radial extension of septum with black line (marked in figure items subscripted with "2" and "4"). Main features of septal junctions (wall structure) marked with arrows: synapticulae $\left(\mathrm{A}_{4}, \mathrm{D}_{4}, \mathrm{E}_{4}, \mathrm{~F}_{4}\right)$, septotheca $\left(\mathrm{C}_{4}\right)$, and fulturae $\left(\mathrm{B}_{4}\right)$.

Fig. 3. Septal arrangement (subscripted with "1"), microarchitecture (subscripted with "2", and "3" [close-up of septal projections]) and microstructure (subscripted with "4") in the examined Psammocora species: P. contigua (A), P. nierstraszi (B), P. profundacella (C), P. superficialis (D), P. stellata (E), P. digitata (F), P. explanulata (G). Basic biomineralization framework characterized by transverse groups of centers of calcification typical of Robusta (see Cuif et. al 2003) highlighted with white arrows whereas radial extension of septum with black lines/arrows in figure items subscripted with " 2 " and "4", respectively. Centers of calcification in all Psammocora species are ca. $20 \mu \mathrm{m}$ in diameter but their arrangement at the growing septal edge is slightly different resulting in some variability in higher level microarchitectural units e.g, strongly bilaterally symmetrical "septal paddles" $\left(\mathrm{D}_{3}, \mathrm{E}_{3}, \mathrm{~F}_{3}\right)$, or more star-like septal protrusions $\left(\mathrm{A}_{3}, \mathrm{~B}_{3}, \mathrm{C}_{3}\right)$. 
siderastreid but C. wellsi (Fig. 4B $_{1}$ which may have one circle of enclosed entosepta, often incomplete, as in P. explanulata. Petaloid septa like those described above in Psammocora form in Coscinaraea, Craterastrea, and are sometimes visible in Horastrea (Fig. 4A, $\mathrm{B}, \mathrm{C})$, but they never form in Siderastrea, Pseudosiderastrea and Anomastraea (Fig. 4D, E, F).

Synapticulae were observed in all the siderastreids (Fig. $4 \mathrm{~A}_{4}, \mathrm{D}_{4}, \mathrm{E}_{4}, \mathrm{~F}_{4}$ ) with the exception of $C$. wellsi which exhibits buttress-like structures joining the septa in all similar to those described for P. explanulata (Fig. $4 \mathrm{~B}_{4}$ ).

Striking differences of skeletal macrostructures were observed between C. wellsi (Fig. 4B) and the congeneric species C. columna (Fig. 4A). Though both species can form petaloid septa and interstomatous septa, they differ in the kind of structures joining the septa, in the nature of the wall and in the presence of tentacular lobes and costae (Table 2). Conversely, C. wellsi bears many similarities with P. explanulata (Table 2). The morphologic affinities between the two species concern the
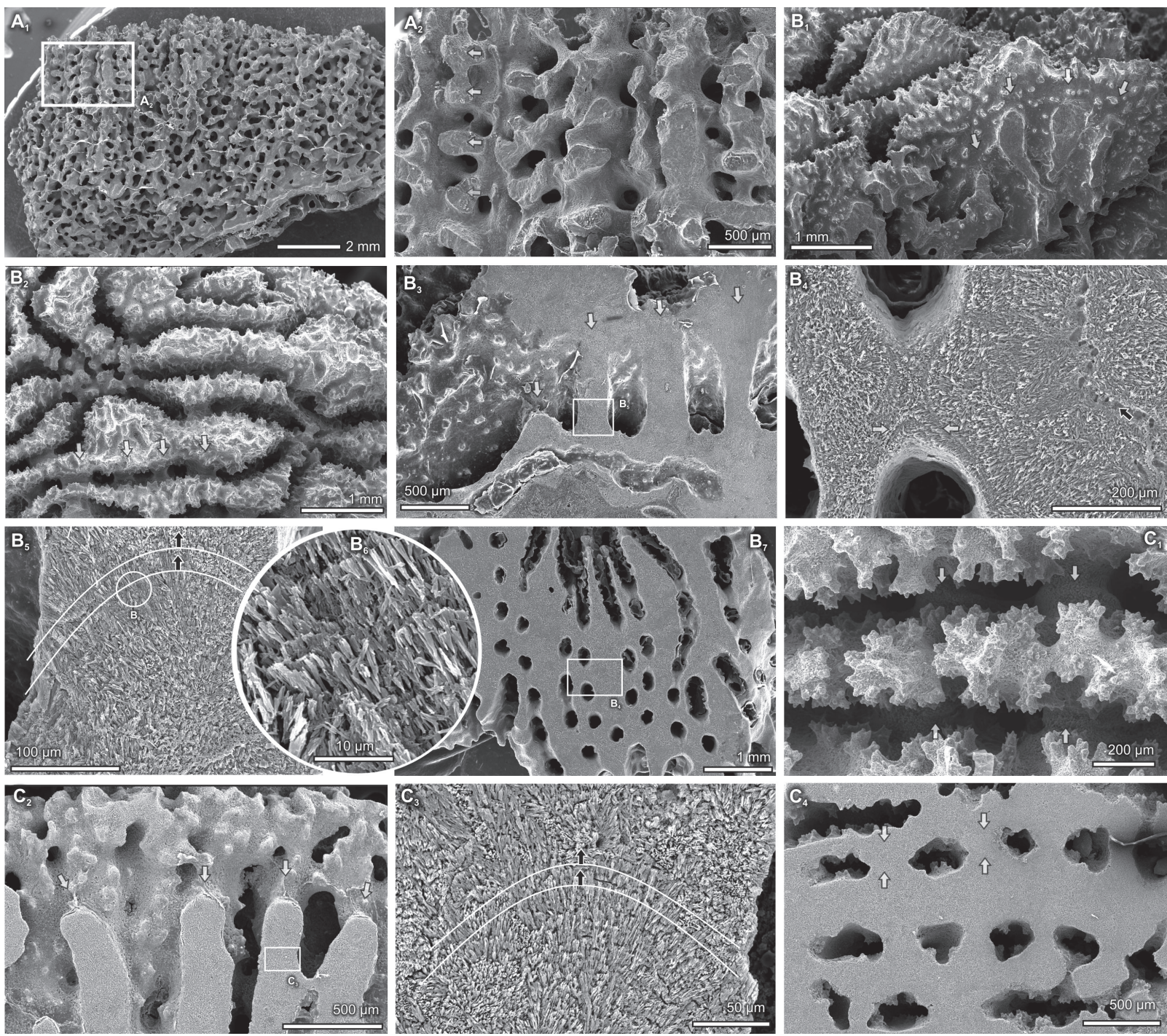

Fig. 5. Synapticulae as typically developed in Psammocora species (illustrated $P$. digitata, A) vs. fulturae in $P$. explanulata (B) and Coscinaraea wellsi (C). Fulturae are continuous bars $\left(\mathrm{B}_{1}, \mathrm{~B}_{3}, \mathrm{C}_{2}\right.$; white arrows) vs. isolated from each other synapticulae $\left(\mathrm{A}_{2}\right.$; white arrows) and develop below septal edge $\left(\mathrm{B}_{1}, \mathrm{~B}_{2}, \mathrm{C}_{2}\right)$ vs. developed at the same level synapticulae $\left(\mathrm{A}_{1}\right)$. Fulturae develop upwards the corallite as indicated by growth direction of the successive layers of fibers $\left(\mathrm{B}_{5,6}, \mathrm{C}_{3}\right)$ in longitudinal $\left(\mathrm{B}_{1}, \mathrm{C}_{2}\right)$ or slightly oblique $\left(\mathrm{B}_{3}\right)$ sections but are formed from deposits growing from adjacent septa (white arrows in $\mathrm{B}_{4}$; centers of calcification of midseptal zone marked with black arrow). Broken $\left(\mathrm{A}_{1,2}-\mathrm{B}_{1,2}\right)$ and polished and etched skeletal sections $\left(\mathrm{B}_{3-7}, \mathrm{C}_{2-4}\right)$. 
presence in both of them of interstomatous septa, tentacular lobes, buttress-like structures joining the septa, and costae on a septothecal wall (Fig. 5B, C; Table 2).

Ridges composed of short spines/granules or well defined paddles are clearly discernible in the two species of Coscinaraea we examined (Fig. $4 \mathrm{~A}_{2,3}, \mathrm{~B}_{2,3}$ ). In other genera, although granules do not form distinct septal paddles, there is tendency to form groups of spines/granules aligned transversely to the septal plane (Fig. $4 \mathrm{C}_{3}, \mathrm{D}_{3}, \mathrm{E}_{3}, \mathrm{~F}_{3}$ ).

Table 2. Skeletal characters in the examined Siderastreidae: 1) Multiple rows of enclosed septa surrounding the calicular fossa; 2) petaloid septa; 3 ) formation of series of calices enclosed by a common wall; 4) interstomatous septa; 5) tentacular lobes; 6) costae; 7) horizontal skeletal elements joining adjacent septa; 8) structure of the wall: $+=$ present; $-=$ absent; $+/-=$ possibly present; $\mathrm{s}=$ synapticulae; $\mathrm{f}=$ fulturae; $\mathrm{sew}=$ septothecal wall; $\mathrm{syw}=$ synapticulothecal wall.

\begin{tabular}{|c|c|c|c|c|c|c|c|c|c|}
\hline Genus & species & 1 & 2 & 3 & 4 & 5 & 6 & 7 & 8 \\
\hline \multirow{7}{*}{ Psammocora } & contigua & + & + & + & - & - & - & $\mathrm{s}$ & syw \\
\hline & nierstraszi & + & + & + & - & - & - & $\mathrm{S}$ & syw \\
\hline & profundacella & + & + & + & - & - & - & $\mathrm{s}$ & syw \\
\hline & superficialis & + & + & + & - & - & - & $\mathrm{s}$ & syw \\
\hline & stellata & + & + & + & - & - & - & $\mathrm{s}$ & syw \\
\hline & digitata & + & + & + & - & - & - & $\mathrm{s}$ & syw \\
\hline & explanulata & $+/-$ & + & - & + & + & + & $\mathrm{f}$ & sew \\
\hline \multirow[t]{2}{*}{ Coscinaraea } & wellsi & $+/-$ & + & - & + & + & + & $\mathrm{f}$ & sew \\
\hline & columna & - & $+/-$ & - & + & - & - & $\mathrm{s}$ & syw \\
\hline Craterastrea & levis & - & $+/-$ & - & - & - & + & $\mathrm{s}$ & sew \\
\hline Horastrea & indica & - & $+/-$ & + & - & - & + & $\mathrm{s}$ & sew \\
\hline Siderastrea & savignyana & - & - & - & - & - & - & $\mathrm{s}$ & syw \\
\hline Pseudosiderastrea & tayamai & - & - & - & - & - & - & $\mathrm{s}$ & syw \\
\hline Anomastraea & irregularis & - & - & - & - & - & - & $\mathrm{S}$ & syw \\
\hline
\end{tabular}

The nature of the wall is not the same in all the Siderastreidae (Table 2). As described above for Psammocora, Siderastrea, Pseudosiderastrea, Anomastraea and C. columna also form epithecal-synapticulothecal wall. In C. wellsi and $H$. indica however, the colony wall has septothecal nature as in P. explanulata. The formation of series of calices enclosed by a common wall present in Psammocora is largely absent in the other siderastreids with the exception of Horastrea. This genus is unique among the siderastreids in forming plocoid instead of cerioid colonies.

The skeletal structures of $C$. levis resemble those of C. columna very closely. The species has been synonymised with the agariciid Leptoseris but the columella structure, septal ornamentation and synapticular pattern, very clearly illustrated and treated in the origi- nal description by Head (1983), leave no doubt on the fact that the species belongs to the Siderastreidae.

\section{The molecular approach}

The obtained electropherograms did not show any signal of intraspecific polymorphism ascribable to the presence of highly divergent gene copies within each sample genome, such as pseudogenes. In order to exclude this hypothesis, a detailed analysis of intraindividual variability would be required (Vollmer and $\mathrm{Pa}$ lumbi, 2004; Marquez et al., 2003). Yet, the presence of pseudogenes has been demonstrated only for the genus Acropora (Marquez et al., 2003), whose elevated polymorphism constitute an exception in Scleractinian genera rather than a common rule (Wei et al., 2006).

The secondary structure of the ITS2 of $H$. indica, $P$. tayamai and $P$. crustacea presented a type I structure with 4 domains (Chen et al., 2004). Conversely F. paumotensis, $H$. limax, P. explanulata, and $P$. contigua fell into the type II model, with 5 domains (domain I appears divided in the two subdomains $\mathrm{I}_{\mathrm{a}}$ and $\mathrm{I}_{\mathrm{b}}$ ). The conserved motif 5'-CRCGGYC-3' and its compensatory bases in stem II described for other family and genera (Chen et al., 2004) was also identified in our sequences. We also identified other conserved regions corresponding to stem IV (motif 5'-GGA -3' and its compensatory bases) and to the terminal stem of domain III (motif 5'- CGCAC -3 ' and its compensatory bases) fixed in all the sequences we obtained except for $S$. savignyana and $P$. tayamai. Alignment was then adjusted imposing these constrains.

The complete alignment consisted of 76 variable positions, 66 of which were parsimony informative. When only sequences of Psammocora, C. wellsi and the Fungiidae were included, the number of variable sites was 32, of which 26 were parsimony informative.

The Statistical Parsimony analysis evidenced five distinct networks (Fig. 6), fixing a maximum value of 8 evolutionary steps allowed by a probability level of 0.95. The main network includes all the Psammocora specimens, the Fungiidae, and the Siderastreidae $C$. wellsi and $H$. indica. The other four networks separated from the main one are monospecific clades of the other Siderastreidae. Within the main clade, two principal subclades are evidenced. One subclade comprises $H$. indica and all the sequences of Psammocora with the exception of $P$. explanulata. The other connects all the Fungiidae sequences plus $P$. explanulata and $C$. wellsi. Three reticulations have been identified, though their 


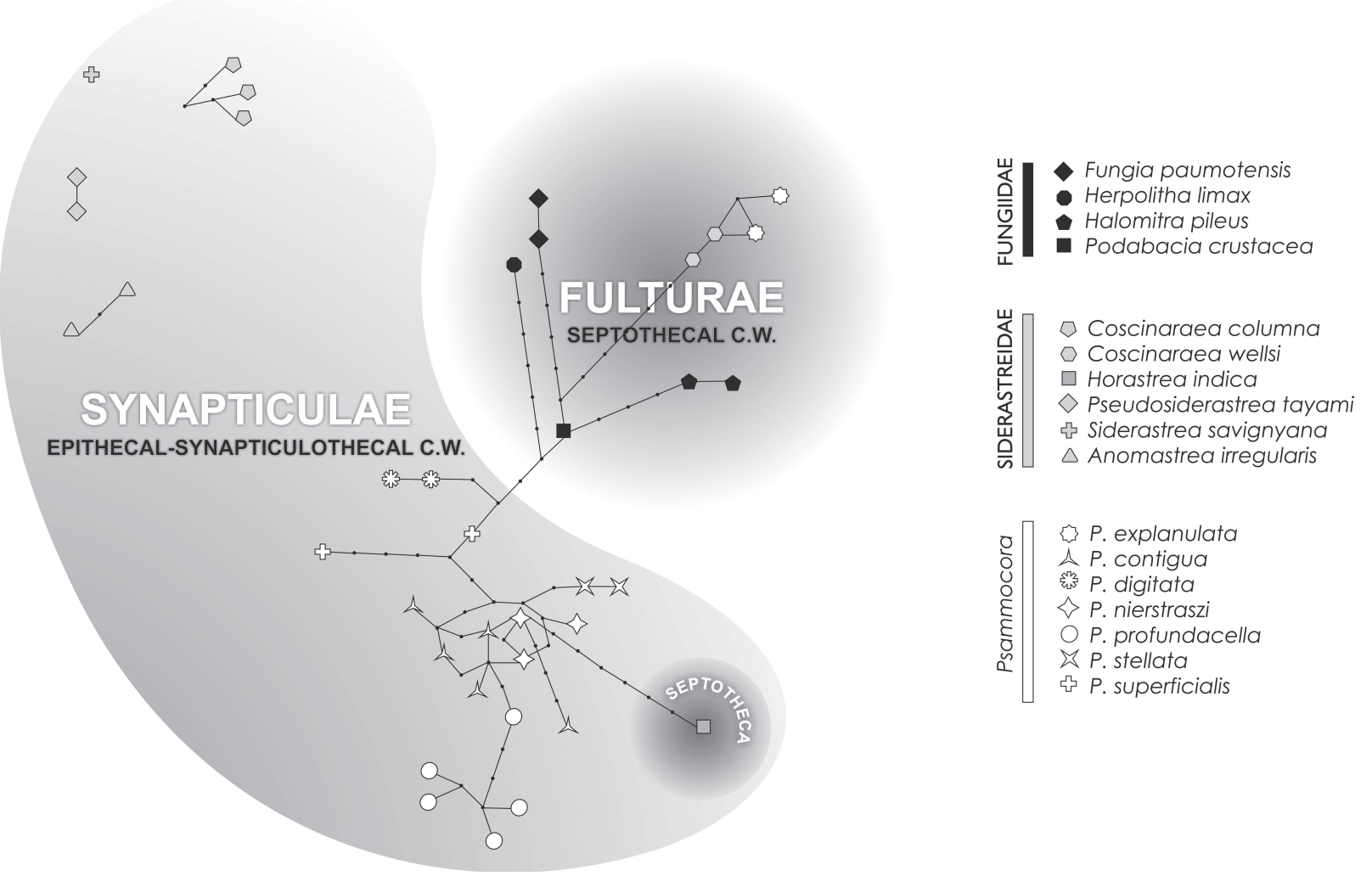

Fig. 6. Phylogenetic networks of ITS2 and 5.8S haplotypes of all the specimens listed in Table 1, calculated under a statistical parsimony criterion. Each polygon or circle in the network represents a haplotype. Each haplotype is univocally coded at species (shape) and family (colour) level since no haplotype is shared between species. One main clade including the haplotypes of all the examined Psammocora species (white filled shapes), Horastrea indica (grey filled square), Coscinaraea wellsi (grey filled hexagon) and of the Fungiidae (black filled shapes) is significantly disconnected from the other Siderastreidae (grey filled shapes). Grey shadows superimposed on the network indicate the nature of the colony wall (septothecal or epithecal-synapticulothecal c.w.) and the kind of structures connecting the septa (synapticulae or fulturae) found in the examined species. C.w. = colony wall.

impact on the overall topology is negligible.

The pairwise sequence divergences have been calculated on the basis of the Tamura and Nei evolutionary model (Tamura and Nei, 1993) accounting for Gamma correction of 0.3012 and equal base frequencies, as output by Modeltest software, and their values for each species estimated. Hereafter average distances for groups of interest are reported. The average distance of the genus Psammocora from the other Siderastreidae is $17.0 \pm 17.3 \%$, and from the Fungiidae is $4.0 \pm 1.1 \%$. The average interspecific distance within the genus Psammocora is $3.0 \pm 1.6 \%$, and within the genus Coscinaraea is $5.6 \pm 0.6 \%$. The average distance between P. explanulata and the other Psammocora species is 5.8 $\pm 0.8 \%$, while the same species shows an average distance of $17.7 \pm 20.6 \%$ from the Siderastreidae excluding
Psammocora, and only of $4.0 \pm 0.6 \%$ from the Fungiidae. Similarly the average distance of $C$. wellsi from Psammocora is $4.8 \pm 1.4 \%$, from the other Siderastreidae is $22.0 \pm 22.1 \%$, and from the Fungiidae is $3.6 \pm$ $0.7 \%$.

The phylogram, obtained according to a Bayesian approach, is reported in Figure 7. An eventual outgroup was not added, since it would introduce significant ambiguities and subjectivity in the alignment of the hypervariable region of ITS2. Consequently, the tree was midpoint rooted. Despite the phylogram adding information to the Statistical Parsimony network, the main patterns are conserved. In particular, 6 clades and subclades could be evidenced, congruent with the inferences obtained by Parsimony analysis. One of the main peculiarity here detected concerns the position of $C$. 


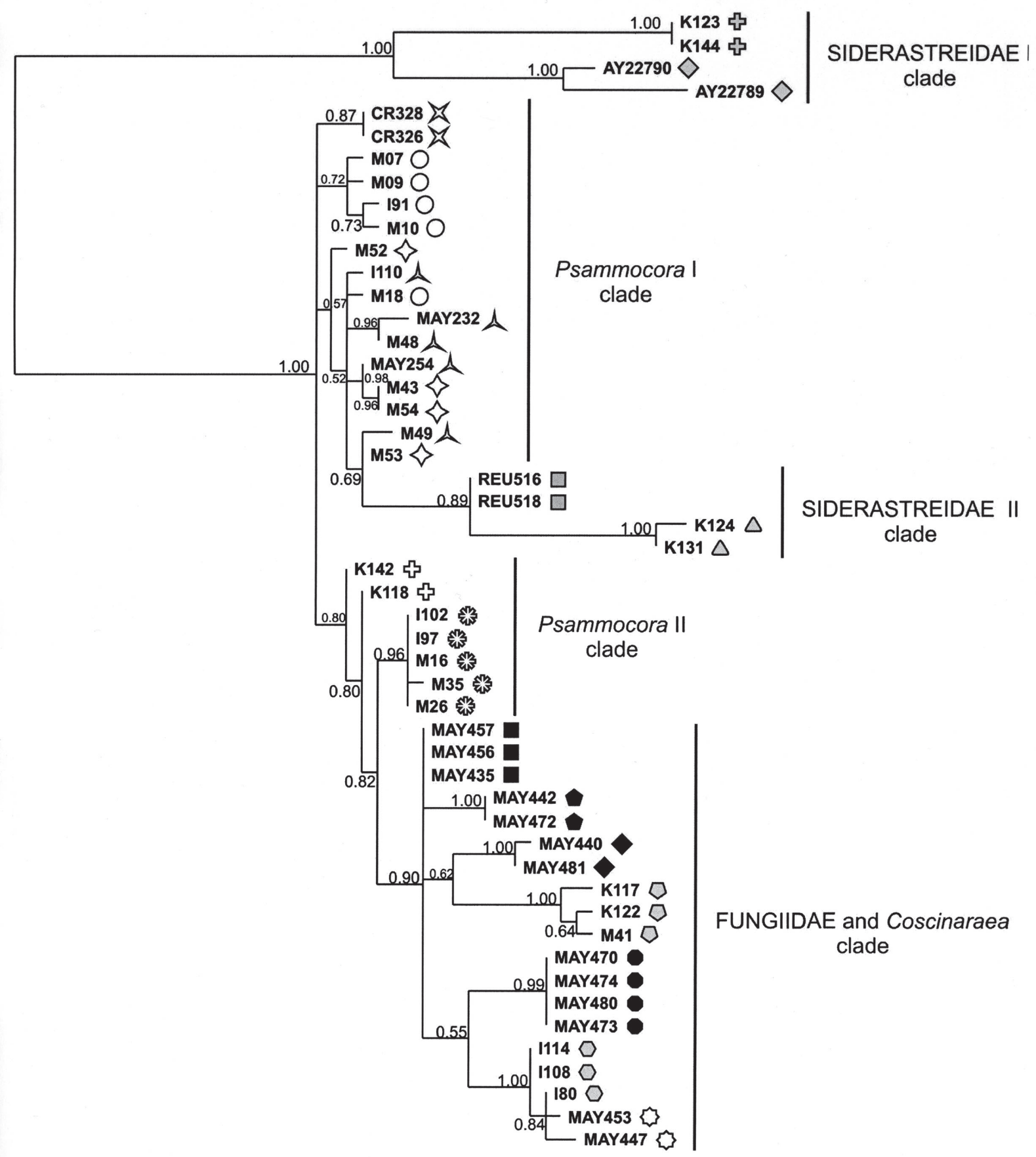

Fig. 7. Phylogenetic tree derived from Bayesian analysis of the partial 5.8S and ITS2 sequences of the studied Scleractinian species. Numbers at each node indicate the posterior nodal probabilities. Symbols explanation for each species as in Fig. 6. 
columna, which appears affine to Fungidae, though the genus remains polyphyletic. Similarly, A. irregularis resulted affine to $H$. indica, yet it appears highly divergent from the main clades of the other Siderastreidae.

\section{Discussion}

\section{Skeletal structures}

The last fifty years of taxonomic history of Scleractinia point out the highly unstable nature of traditional, skeletal-based phylogenetic hypotheses. The case of Psammocora and the siderastreids is an excellent example of this (Fig. 1). Until recently the use of no other criteria than skeletal structures has resulted in arbitrary taxonomic frameworks. Moreover the proposed phylogenies were based on the most prominent skeletal components of the scleractinian corallum only, i.e. mostly septal features. Such biased perspective was, in turn, a possible reason for the underestimation of other skeletal structures as informative characters. In the peculiar case of the genus Psammocora even the septal features have been underestimated. The unique pattern of septa arrangement typical of the genus has been largely neglected in the last sixty years of published literature. The multiple rows of enclosed entosepta are missing in any other siderastreid genus including Coscinaraea, while they can be found in some Fungiidae. Such morphologic affinity between Psammocora and the Fungiidae seems to be corroborated by phylogenetic proximity as shown by the molecular results in our study. The lack of consideration of this macro-morphologic character has hence lead on the one hand to a biased evaluation of the structural affinities with the other siderastreid genera, while, on the other hand, it has also lead to the widespread use of incorrect terminology. The mesh of ento- and exosepta typical of Psammocora has been often erroneously referred to as the coenosteum while the extrapolypal tentacles above it as the coenenchyma (Milne Edwards and Haime, 1851; Klunzinger, 1879; Van der Horst; 1922; Hoffmeister, 1925; Yabe et al., 1937). Septocostae have also been recognised by various authors in Psammocora (Milne Edwards and Haime, 1851; Vaughan, 1907; Vaughan, 1918; Veron and Pichon, 1976; Veron, 2000) despite the absence of such structures in the genus.

Thecal structures were only superficially described in Psammocora species, and the structure of the colony/ calice wall in Psammocora has not been mentioned at all in the original description of the genus (Dana, 1846).
According to Milne. Edwards and Haime calices in Psammocora are "sans muraille proprement dites" ("without proper wall", 1851: 66), an opinion shared also by Vaughan and Wells (1943: 128) who stated that "corallite wall is absent, calicular boundaries sometimes marked by synapticular rings". Other authors have referred to the wall in Psammocora as "indistinct or wanting" (Verrill, 1866: 330) or "indistinct" (Veron, 2000: vol. 2, 144) without specifying its nature. Gardiner (1898: 358) described a "false wall formed by synapticula and trabeculae", and Chevalier and Beauvais (1987: 704) agreed with the former on the presence of a poorly defined and porous synapticular wall in Psammocora. Also thecal structures of the siderastreids have not been described thoroughly. Nonetheless the occurrence of synapticulothecal calicular wall was considered one of the diagnostic characters of the family (Wells 1956: F383).

The results of our study revealed significant differences between colony and calicular walls among typical Psammocora species and some siderastreids (Table 2) that seem to agree with the results of our molecular studies (Table 3 and Figure 6). Since the use of some of the morphological terms in modern scleractinian literature is often imprecise some key characteristics of these structures are discussed hereafter.

Colony wall (epitheca, complex wall structures, septotheca)

The colony wall and its distinction from the inter-calicular thecal structures have rarely been comprehensively treated. In the Scleractinia colony walls are most commonly comprised of epithecal composite structures: epitheca, the most external structure of the colony rim, is associated with other septa-connecting structures (epithecal-dissepimental, epithecal-trabeculothecal, epithecal-septothecal, epithecal-synapticulothecal walls; see Roniewicz and Stolarski, 1999). Growth acceleration of radial structures often results in the disappearance of the continuous epithecal cover and leads to the formation of other wall types, most typically septothecal.

In the Psammocora species we studied (with the exception of $P$. explanulata) colonies form epithecalsynapticulothecal wall. Conversely in $P$. explanulata the colony wall in adult colonies has a septothecal nature (early juvenile stages of colony wall formation have not been examined). The same septothecal wall develops also in the other taxa forming together with $P$. explanulata a clade in the molecular network shown in Figure 6 (i.e., fungiids and C. wellsi). 
Calice thecal structures (synapticulae, fulturae, adtrabecular bars)

In many scleractinian taxa, especially those that form a porous skeleton, adjacent septa may join via crossbarlike rods called synapticulae (Vaughan and Wells, 1943:39). Synapticulae can be aligned across the adjacent interseptal spaces to form synapticular rings that in turn, if arranged one above the other, create a (inter)corallite wall called synapticulotheca. In the Fungiidae, Vaughan and Wells (1943) and Wells (1956) distinguished a synapticulothecal wall that could secondarily be thickened to form septotheca. A synapticulothecal wall was also recognised by the same authors in the Siderastreidae and in the Thamnasteriidae (that included Psammocora). Wells (1956: F385) mentioned that septal connections between of fungiid consisted of "compound synapticulae". Later Gill (1980) showed that the "simple" synapticulae widely occurring among scleractinians are not homologous to the "compound" synapticulae found in the Fungiidae. Hence, to avoid mixing up synapticular terminology, the same author coined the term "fulturae". Fulturae are continuous buttress-like structures occurring on septal faces developed below septal edge (see Gill, 1980: pl. 1:1 Fungia; Hoeksema, 1989: figs. 652 Herpolitha; 656 Sandalolitha; 664 Lithophyllon) which differ from the synapticulae, typically isolated from each other and developed often near the septal edge (Gill, 1977; 1980). Moreover, while synapticulae are commonly parallel to the trabeculae orientation, fulturae direction is mostly independent from that of septal trabeculae. Fulturae are arranged normally to distal septal margins and can be fused with similar structures on adjacent septa (Gill, 1980: 305). In longitudinal sections fulturae show fibrous layers arranged into arched zones (Gill, 1980: fig. 4a), which diverge from the "axial area of divergence".

The problem of homology between the synapticular structures became more complex as Roniewicz (1982) described vertically continuous, longitudinal interseptal structures on septal faces of the Jurassic coral Thamnasteria concinna (Goldfuss, 1826). According to Roniewicz (1982: 183) these structures, named adtrabecular bars, are "to a great extent, similar to fulturae" as they develop below the septal edge and are arranged normally to distal septal margins. However, adtrabecular bars differ from fulturae in the course of growth that follows that of particular septal trabeculae only, and in the consistent attachment to similar structures on adjacent septa.
Among the taxa examined in this paper, we distinguished a typical synapticulotheca in the corallites of all the Psammocora species (except P. explanulata), and all the siderastreids (except Coscinarea wellsi). The solid bars joining septa of $P$. explanulata and $C$. wellsi bear fulturae/adtrabecular bars characteristics: they develop below septal edge, are arranged normally to distal septal margins. They show arched zones of fibrous layers in longitudinal section, and exhibit ad-septal formation of their fibrous layers joining with a suture in the middle of the interseptal zone (Fig. 5B4) in transverse sections. The bar width in P. explanulata and $C$. wellsi is several times larger than the diameter of "calcification centers" on neighbouring septa (Fig. 5B4), hence their longitudinal extension follows the course of series of septal trabeculae. Arrangement of the solid bars in P. explanulata and C. wellsi resembles strikingly that of adtrabecular bars in the Jurassic T. concinna. In Thamnasteria, however, each adtrabecular bar is associated with a single septal trabecula. Noteworthy, these species all form thamnasteroid colonies, whose architecture may impose some constructional solutions of the solid bars different from that of solitary fungiid bearing typical fulturae. Conversely, even typical fungiid fulturae can occasionally follow the course of septal trabeculae (Gill, 1980: 304) and join with suture in interseptal zone. Consequently, there is no clear-cut distinction between adtrabecular bars and fulturae. We plan to investigate this problem comprehensively in a project that will focus on emergence of Psammcora-like structures among the fossil scleractinians. In this paper, however, we acknowledge that all mentioned buttresslike structures (fulturae sensu lato) share the same basic features (solid structure, regular spacing, development below the septal edge, arrangement normal to distal septal margin) whereas some structural differences may result from different colony specialization among the examined taxa. Possible homology between fulturae sensu lato is supported by our molecular results that group together fulturae-bearing fungiids, Psammocora explanulata and Coscinarea wellsi (Fig. 6).

Septal microarchitecture and microstructure

Recent molecular studies have challenged many longheld concepts concerning the evolution and systematic of scleractinian corals. One of the major outcomes of 28S rRNA and 16S rRNA studies is a phylogenetic hypothesis based on the occurrence of two major clades of Scleractinia: the Complexa and the Robusta clades, (in terminology by Kerr 2005) and few minor clades 
(Romano and Palumbi, 1996; Romano and Cairns, 2000). Species of Psammocora, Coscinaraea and fungiids reveal affinity with the Robusta. Interestingly the Atlantic species Siderastraea siderea (the type species of the genus) is related to the Complexa clade (Romano and Cairns, 2000). Cuif et al. (2003) in a combined morpho-molecular study of 42 scleractinian species suggested that the occurrence of short series of calcification centers arranged transversally to the main septal course might be a skeleton-based synapomorphy of corals in the Robusta clade. Our survey of the microarchitectural and microstructural skeletal traits of Psammocora and of the Indo-Pacific siderastreids, not included in Cuif et al. (2003), also revealed that the formation of short series of calcification centers aligned transversely to the main course of septum is a prevailing septal biomineralization trait of these corals. In some of the specimens we examined, these transverse series were particularly distinct and expressed in septal microarchitecture as well defined paddles (i.e. $P$. superficialis, P. digitata, P. explanulata, and Coscinaraea) (Figs. 3: $\left.\mathrm{D}_{2-3}, \mathrm{E}_{2-3}, \mathrm{~F}_{2-3} ; 4: \mathrm{A}_{2-3}, \mathrm{~B}_{2-3}\right)$. All septal paddle-bearing species of Psammocora are positioned closely in the molecular network (Fig. 6). The possible taxonomic value of this character needs to be carefully evaluated in future quantitative studies of interspecific and intercolony variation of septal microarchitecture.

\section{Phylogeny of Psammocora and the Siderastreidae}

The utility of ITS2 marker for phylogenetic discrimination within the Scleractinia has been highly debated (van Oppen et al., 2002; Vollmer and Palumbi, 2004; Chen et al., 2004), in parallel to its growing use (Hunter et al., 1997; Lopez and Knowlton, 1997; Medina et al., 1997; Odorico and Miller, 1997; van Oppen et al., 2000, 2002; Diekmann et al., 2001; Rodriguez-Lanetty and Hoegh-Guldberg, 2002; Chen et al., 2004). High levels of divergence within the genus Acropora and, more generally, in the taxa of the Complexa clade (Romano and Palumbi, 1996; Romano and Cairns, 2000) would prevent the use of ITS2 as a reliable marker due to retention of ancient lineages predating the origin of the species. Conversely the utility of ITS2 has been proved: 1) at the interfamiliar and intergeneric level when considering all the taxa included in the Robust clade (Diekmann et al., 2001; Rodriguez-Lanetty and Hoegh-Guldberg, 2002; Chen et al., 2004), and 2) for the identification of the conserved region implied in the organization of the secondary structure of ITS2, re- garded as an indispensable step for a reliable sequence alignment (Chen et al., 2004). Both conditions were met in the present study.

The minimum spanning network and the phylogram evidenced the presence of a wide range of divergence between and within the considered taxa. Some incongruences between the two phylogenetic representations are evidenced, mainly due to the different approaches they employ. However, common patterns could be easily evidenced. At the family level our results show that the Fungiidae are grouped in a monophylum though being paraphyletic to the genus Coscinaraea (C. wellsi according to both the approaches) and P. explanulata.

Conversely, the Siderastreidae are polyphyletic, highly divergent and characterised by six subclades, five of them significantly divergent according to Statistical Parsimony analysis. The high values of genetic distances detected between the species of this family confirm a deep phylogenetic structure of the Siderastreidae. In particular, the deepest divergence detected separates P. tayamai and Siderastrea savignyana from the remaining genera. This divergence was also suggested by Chen et al. (2004) and Romano and Cairns (2000), using respectively ITS2 on $P$. tayamai and $P$. contigua, and 28S on Pseudosiderastrea and Siderastrea. Conversely, analysis of the mtDNA 16S (Romano and Cairns, 2000; Le Goff-Vitry et al., 2004) grouped P. stellata, P. contigua and an unidentified specimen of Coscinaraea in a single clade with the Fungiidae, thus suggesting the phylogenetic affinity of these taxa. Both these inferences are congruent with our results. Their apparent contradiction is de facto due to their partial and non overlapping coverage of the species composition of the family Siderastreidae.

The phylogenetic relationships within the siderastreids showed that both Psammocora and Coscinaraea are not monophyletic and share a lineage at least in paraphyly with the Fungiidae, thus evidencing strong divergences within the two genera. The monophyletic status of both genera has never been investigated by means of molecular techniques before. Pandolfi (1992) while providing a cladistic biogeographic analysis of Coscinaraea also reconstructed the phylogeny of Psammocora and of the Siderastreidae using skeleton macrostructural characters. He concluded that Coscinaraea and Psammocora are monophyletic and closer to each other than to any other genus in the family. However, among the morphological characters he used, he did not include the microstructure of elements connecting septa, or other characters that proved useful in our study. Moreover, it is worth noting that the close phylogenetic 
relationship between Psammocora and Coscinaraea evidenced in previous studies based on 16S mtDNA (Romano and Palumbi, 1996; Romano and Cairns, 2000; Le Goff-Vitry, 2004) is only in apparent contrast with our results. Such a close genetic affinity between the two genera was biased, since based in each cited study on the same unidentified Coscinaraea specimen (Genbank L76001) and a few Psammocora sequences. Moreover, the resolution power of mitochondrial markers is not sufficient to reveal phylogenetic differences at inter-specific level (Shearer et al., 2002). The polyphyletic status of the two genera evidenced in our study could hence be explained by the application of a more variable molecular marker, a rDNA fragment, to a wider data set of species of the two genera.

The morphology based affinities within the siderastreids sensu Veron (2000), and between Psammocora and Coscinaraea in particular, are most unlikely to result from a real homology of the characters, and thus contrast with molecular data. Romano and Cairns (2000) were driven to the same conclusion for the suborder Fungiina, but failed to detect the same discrepancy within the families of this suborder. In the case of the Siderastreidae this was due to the incomplete coverage of species of the family. An indication of the potential polyphyly of the Siderastreidae was given in the work of Le Goff-Vitry et al. (2004) and in the combined morphological and molecular approach proposed by Kerr (2005). This last approach provided the fusion of the results of previous phylogenetic analysis based on different molecular markers and of morphology based phylogenies in a single supertree. Differently, our work provides a phylogenetic inference spanning most of the genera and species of the family using a single molecular marker and a combined morphological approach.

At the intrageneric level, the genus Psammocora showed a low divergence compared to the average interspecific distances detected for other genera of the Robusta clade (Chen et al., 2004), while Coscinaraea showed higher values of divergence. Within Psammocora the resolution at species level was only partially evidenced in our results. Specific clades could be distinguished unambiguously for $P$. digitata, and P. stellata. Conversely $P$. contigua and $P$. nierstraszi haplotypes were linked by reticulation and their relationship cannot be resolved. Intra-individual analysis is required to clarify whether this could indicate incomplete lineage sorting at species level or hybridization. The close phylogenetic relationship of $P$. explanulata and $C$. wellsi emerging from our study, however, matches the above mentioned skeletal structures affinity and suggests that the two species constitute a distinct lineage with stricter affinity with Fungiidae than with the family and genera they have been so far assigned to.

Therefore, the results of this study suggest the need for a revision of the systematic relationships within the genus Psammocora, Coscinaraea and between the families of the Fungiina.

\section{Conclusions}

As a result of the combined investigation of skeletal morphology and molecular phylogeny we can draw the following conclusions:

1. The genus Psammocora is not monophyletic. All the species we examined except $P$. explanulata share common macro and micro structural characters and result phylogenetically closely related. P. explanulata on the other hand differs from all the other species in the structure of the wall, presence of fulturae, costae and interstomatous septa between adult corallites.

2. The genus Coscinaraea is not monophyletic. The two species we examined present different macro and micro structural characters with respect to the structure of the wall, presence of fulturae and costae, and are genetically distant. C. wellsi is more closely related to the Fungiidae considered in this study than to the congeneric C. columna.

3. C. wellsi and P. explanulata are structurally and genetically closer to each other and to the Fungiidae than to any of the other Siderastreidae. The two species share macro and micro structural characters which are not found in any other of the Siderastreidae (i.e. interstomatous septa, tentacular lobes, costae, fulturae) and are phylogenetically very close to each other. Moreover their phylogeny shows stricter affinity with the Fungiidae than with Psammocora, Coscinaraea, or any other Siderastreidae.

4. The Siderastreidae sensu Veron (2000) are not monophyletic and deeply divergent. The genera Psammocora and Coscinaraea are closer to the Fungiidae than to the Siderastreidae. The genera Siderastrea and Pseudosiderastrea are those that share the least characters in common with the other genera in the family, and that are phylogenetically more distant from the others and closer between them.

Our study shows that care should be taken in inferring family level phylogenies from one or two species per 
genus only until the monophyly of the traditionally recognised genera in the Scleractinia is proved. Moreover, it confirms that, despite the clear advances brought by the use of molecular techniques, comprehensive skeletal studies including previously neglected or misidentified macrostructural and microstructural characters can still provide new information and useful tools for the study of the phylogenetic relationships within the Scleractinia.

\section{Acknowledgements}

The authors wish to thank P. Tisseyre (Perpignan) for sequencing, J. Cortes (San Pedro) for his kind help in providing P. stellata from Costa Rica, Yannick Geynet (St. Denis) and the Corail Plongée staff for their assistance in the collection on $\mathrm{H}$. indica in La Réunion. Specimens from the Maldives were collected thanks to the kind support of P. Colantoni (Urbino) and the logistics of M. Sandrini (Verbania) of Albatros Top Diving. Material from Indonesia was collected thanks to the support of $\mathrm{G}$. Bavestrello (Ancona) and M. Boyer (Manado) of Celebes Divers. We are also grateful to A. Geraci (Milano), D. Obura (Mombasa), F. Seguin (Mamoudzou) for their help with field work and sampling, B. Hoeksema (Leiden) for useful comments on the Fungiidae, M. Casiraghi (Milano) for his help in the initial phase of the molecular work and for constructive comments on the manuscript, A. Gittenberger (Leiden) for providing Esper's original description and illustrations of $P$. contigua. We thank B. Hoeksema (Leiden) for access to the Naturalis coral collections, R. Van Soest and E. Beglinger to the ZMA collections, A. Cabrinovic and M. Lowe (London) to the NHM collections, R. Preece and R. Symonds (Cambridge) from UMZC for the type specimen loan, N. Jun (Sendai) for his help with the type material deposited at IGPTU. We are grateful to the Fédération de Recherche Biologie et Ecologie Tropicale et Mediterranéenne (FR 2577 CNRS) Université de Perpignan, to IKBS Université de La Réunion, and to Bernard Thomassin (Marseille) and the GIS Mayotte for supporting this study.

\section{References}

Alloiteau J. 1952. Anthozoaires II: Madréporaires post-paléozoiques. Traité de Paléontologie. Paris: Masson.

Cairns SD, Hoeksema BW, Land J van der. 1999. Appendix: List of Extant Stony Corals. Atoll Research Bulletin 459: 13-46.

Carpenter KE, Harrison PL, Hodgson G, Alsaffar AH, Alhazeem SH. 1997. The Corals and reef fishes of Kuwait. Kuwait City: Kuwait Institute for Scientific Research, Environmental Public Authority.

Chen CC, Chang CC, Wei NV, Chen CH, Lein YT, Dai CF, Fallace C. 2004. Secondary structure and phylogenetic utility of ribosomal internal spacer 2 (ITS2) in Scleractinian corals. Zoological Studies 43(4): 759-771.
Chevalier JP, Beauvais L. 1987. Ordre des Scleractiniaires, p. 403-764. In: Grasse PP (ed.), Traite de Zoologie, Cnidaires, Anthozoaires. Masson, Paris.

Clement M, Posada D, Crandall K. 2000. TCS: a computer program to estimate gene genealogies. Molecular Ecology 9: 1657-1660.

Cuif JP, Lecointre G, Perrin C, Tillier A, Tillier S. 2003. Patterns of septal biomineralization in Scleractinia compared with their 28S rRNA phylogeny: a dual approach for a new taxonomic framework. Zoologica Scripta 32: 459-473.

Dana JD. 1846. Zoophytes. U.S. Exploratory Expeditions 18361842. 7: 1-740.

Diekmann OE, Bak RPM, Stam WT, Olsen JL. 2001. Molecular genetic evidence for probable reticulate speciation in the coral genus Madracis from a Caribbean fringing reef slope. Marine Biology 139: 221-233.

Gardiner SM. 1898. On the Fungid corals collected by the author in the South Pacific. Proceedings of the Zoological Society of London 3: 525-539.

Gill GA. 1977. Problèmes de structure, de classification et d'écologie chez les Hexacoralliaires fossiles et actuels. $2^{\text {nd }}$ Part. Travaux inédits et Résumé. 256 pp. Unpublished Ph.D. Thesis, Pierre et Marie Curie University, Paris 6.

Gill GA. 1980. The fulturae ("compound synapticulae"), their structure and reconsideration of their systematic value. Acta Palaeontologica Pol. 25: 301-310.

Goertzen LR, Cannone JJ, Gutell RR, Jasen RK. 2003. ITS secondary structure derived from comparative analysis: implications for sequence alignment and phylogeny of the Asteraceae. Molecular Phylogenetics and Evolution 29: 216-234.

Goldfuss A. 1826. Petrefacta Germaniae. Düsseldorf: Arnz.

Gutell RR, Larson N, Woese CR. 1994. Lessons from an evolving rRNA: $16 \mathrm{~S}$ and $23 \mathrm{~S}$ RNA structures from a comparative perspective. Microbiological Reviews 58: 10-26.

Hall TA. 1999. BioEdit: a user-friendly biological sequence alignment editor and analysis program for Windows 95/98/NT. Nucleic Acids Symposium Series 41: 95-98.

Head SM. 1983. An undescribed species of Merulina and a new genus and species of siderastreid coral from the Red Sea. Journal of Natural History 17: 419-435.

Hershkovitz MA, Zimmmer EA. 1996. Conservation pattern in angiosperm rDNA ITS2 sequences. Nucleic Acids Research 24: $2857-2867$.

Hoeksema BW. 1989. Taxonomy, phylogeny and biogeography of mushroom corals (Scleractinia: Fungiidae). Zoologische Verhandelingen Leiden 254: 1-295.

Hoffmeister JE. 1925. Some corals from American Samoa and the Fiji Islands. Papers from the Department of Marine Biology of the Carnegie Institution of Washington. 22: 1-90.

Horst CJ van der. 1922. The Madreporaria of the Siboga Expedition. Siboga-Expeditie. 16: 45-75.

Hunter CL, Morden CW, Smith CM. 1997. The utility of ITS sequences assessing relationships among zooxanthellae and corals. Proceedings of the 8th International Coral Reef Symposium 2: 1599-1602.

Inskipp T, Gillett HJ. 2005. Checklist of CITES species and Annotated CITES Appendices and reservations. Compiled by UNEPWCMC. CITES Secretariat, Geneva, Switzerland and UNEP-WCMC, Cambridge. 
Kerr AM. 2005. Molecular and morphological supertree of stony corals (Anthozoa: Scleractinia) using matrix representation parsimony. Biological Reviews 80: 1-16.

Klunzinger CB. 1879. Die Korallthiere des Rothen Meeres. Berlin: Gutmann'schen Buchhandlung.

Le Goff-Vitry MC, Pybus OG, Rogers AD. 2004. Genetic structure of the deep-sea coral Lophelia pertusa in the North East Atlantic revealed by microsatellites and ITS sequences. Molecular Ecology 13(3): 537-549.

Lopez JV, Knowlton N. 1997. Description of Montastrea coral sibling species with multiple genetic loci. Proceedings of the 8th International Coral Reef Symposium 2: 1613-1618.

Matthai G. 1948a. On the Mode of Growth of The Skeleton in Fungid Corals. Royal Society of London Philosophical Transactions 233(597): 177-195.

Matthai G. 1948b. Colony formation in fungid corals. I Pavona, Echinophyllia, Leptoseris and Psammocora. Royal Society of London Philosophical Transactions. 233(598): 201-231.

Medina M, Weil E, Szmant AM. 1999. Examination of the Montastrea annularis species complex (Cnidaria: Scleractinia) using ITS and COI sequences. Marine Biotechnology 1: 89-97.

Milne Edwards H, Haime J. 1851. Recherches sur les polypiers. 6 me Mémoire. Monographie des Fongides. Annales des Sciences Naturelles, Paris, Series 3, 15:73-144.

Odorico DM, Miller DJ. 1997. Variation in the Internal Transcribed Spacers and 5.8S rDNA among five species of Acropora (Cnidaria; Scleractinia): patterns of variation consistent with reticulate evolution. Molecular Biology and Evolution 14(5): 465-473.

Pandolfi J. 1992. Successive isolation rather than evolutionary centres for the origination of Indo-Pacific reef corals. Journal of Biogeography 92: 593-609.

Pillai CSG, Scheer G. 1976. Report on the Stony Corals from the Maldive. Zoologica (Stuff) 126: 1-83.

Posada D, Crandall KA. 1998. MODELTEST: testing the model of DBA substitution. Bioinformatics 14: 817-818.

Rodriguez-Lanetty M, Hoegh-Guldberg O. 2002. The phylogeography and connectivity of the latitudinally widespread scleractinian coral Plesiastrea versipora in the Western Pacific. Molecular Ecology. 11: 1177-1189.

Romano SL, Cairns SD. 2000. Molecular phylogenetic hypotheses for the evolution of scleractinian corals. Bulletin of Marine Science 67: 1043-1068.

Romano SL, Palumbi SR. 1996. Evolution of scleractinian corals inferred from molecular systematics. Science 271: 640-642.

Roniewicz E, Stolarski J. 1999. Evolutionary trends in the epithecal scleractinian corals. Acta Palaeontologica Polonica 44: 131-166.

Roniewicz E. 1982. Pennular and non-pennular Jurassic scleractinians - some examples. Acta Palaeontologica Polonica 27: 157-193.

Rozas J, Rozas R. 2001. DnaSP 3.52 DNA Sequence Polimorphism, Software for nucleotidic polymorphism analysis. Universitat de Barcelona.

Shearer TM, van Oppen MJH, Romano SL, Wörheide G. 2002. Slow mitochondrial DNA sequence evolution in the Anthozoa (Cnidaria) Molecular Ecology 11: 2475-2487.
Scheer G, Pillai CSG. 1983. Report on the stony corals from the Red Sea, Zoologica 133: 1-198.

Sheppard CRC, Sheppard ALS. 1991. Corals and coral communities of Saudi Arabia. Fauna of Arabia 12: 1-170.

Sheppard CRC. 1991. The reef and soft-substrate coral fauna of Chagos, Indian Ocean. Journal of Natural History 15: 607621.

Sheppard CRC. 1998. Corals of the Indian Ocean. CD. Stockholm: SIDA Stockholm University.

Stolarski J, Roniewicz E. 2001. Towards a new synthesis of evolutionary relationships and classification of Scleractinia. Journal of Paleontology 75: 1090-1108.

Stolarski J. 2003. Three-dimensional micro- and nanostructural characteristics of the scleractinian coral skeleton: A biocalcification proxy. Acta Palaeontologica Polonica 48: 497-530.

Tamura K, Nei M. 1993. Estimation of the number of nucleotide substitutions in the control region of mitochondrial DNA in humans and chimpanzees. Molecular Biology and Evolution 10: 512-526.

Templeton AR, Crandall KA, Sing CF. 1992. A cladistic analysis of phenotypic associations with haplotypes inferred from restriction endonuclease mapping and DNA sequence data. III. Cladogram estimation. Genetics 132: 619-633.

Templeton AR, Sing CF. 1993. A cladistic analysis of phenotypic associations with haplotypes inferred from restriction endonuclease mapping. IV. Nested analysis with cladogram uncertainty and recombination. Genetics 134: 659-669.

Thompson JD, Gibson TJ, Plewniak F, Jeanmougin F, Higgins DG. 1997. The ClustalX windows interface: flexible strategies for multiple sequence alignment aided by quality analysis tools. Nucleic Acids Research 24: 4876-4882.

Van Oppen MJH, Willis BL, van Rheede T, Miller DJ. 2002. Spawning times, reproductive compatibilities and genetic structuring in the Acropora aspera group: evidence for natural hybridization and semi-permeable species boundaries in corals. Molecular Ecology 11: 1363-1376.

Van Oppen MJH, Willis BL, Vugt HWJ, Miller DJ. 2000. Examination of species boundaries in the Acropora cervicornis group (Scleractinia, Cnidaria) using nuclear DNA sequence analysis. Molecular Ecology 9: 1363-1373.

Vaughan TW. 1907. Recent Madreporaria of the Hawai'ian Islands and Laysan. Bulletin of the United States National Museum 59: 1-427.

Vaughan TW. 1918. Some shallow-water corals from Murray Island (Australia), Cocos-Keeling Island, and Fanning Island. Papers from the Department of Marine Biology of the Carnegie Institution of Washington. 213: 49-234.

Vaughan TW, Wells JW. 1943. Revision of the suborders, families, and genera of the Scleractinia. Geoogical Society of America, Special Paper 44: 1-363.

Veron JEN, Pichon M. 1976. Scleractinia of Eastern Australia Families Thamnasteriidae, Astrocoeniidae, Pocilloporidae. AIMS Monograph Series 1: 1-86

Veron JEN, Pichon M. 1980. Scleractinia of Eastern Australia Families Agaraciidae, Siderastreidae, Fungiidae, Oculinidae, Merulinidae, Mussidae, Pectiniidae, Caryophylliidae, Dendrophylliidae. AIMS Monograph Series 4: 1-471. 
Veron JEN. 1995. Corals in Space and Time: the Biogeography and Evolution of the Scleractinia. University of New South Wales Press.

Veron JEN. 2000. Corals of the world. Townsville: Australian Institute of Marine Science.

Verrill AE. 1866. On the polyps and corals of Panama with descriptions of new species. Proc. Boston Soc. Nat. Hist. 10: 325-357.

Vollmer SV, Palumbi SR. 2004. Testing the utility of internally transcribed spacer sequences in coral phylogenetics Molecular Ecology 13: 2763-2772.

Wells JW. 1956. Scleractinia. In: Moore RC (ed.) Treatise on Invertebrate Paleontology, part F (Coelenterata), F328-F444. The University of Kansas Press, Lawrence, Kansas.

White TJ, Bruns T, Lee S, Taylor J. 1990. Amplification and direct sequencing of fungal ribosomal RNA genes for phylogenetics. In: Innis MA, Gelfand DH, Sninsky JJ, White TJ (eds) PCR protocols. A guide to methods and application. Academic Press Inc. San Diego, California, USA.
Yabe H, Sugiyama T, Eguchi M. 1936. Recent reef-building corals from Japan and the South Sea islands under the Japanese mandate. Science Reports of the Tohoku Imperial University, Sendai, Japan. 1(1): 1-66.

Yabe H, Sugiyama T. 1937. Two new species of reef-building corals from Yoron-zima and Amami-O-sima. Proceedings of the Imperial Academy Tokyo 8: 425-429.

Yonge CM. 1930. Studies on the physiology of corals. 1. Feeding mechanisms and food. Scientific Report of the Great Barrier Reef Expedition 1928-1929. 1(2): 13-57.

Zuker M. 2003. Mfold web server for nucleic acid folding and hybridization prediction. Nucleic Acids Research 31(13): 3406-3415.

Received: 1 June 2006

Accepted: 27 November 2006 